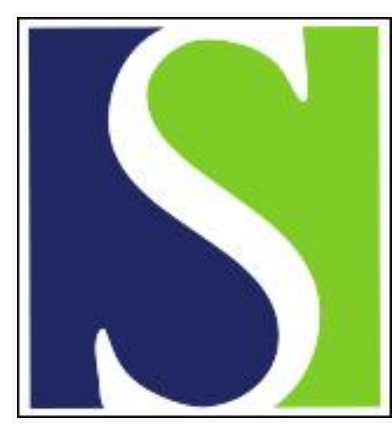

Scand J Work Environ Health 1991;17(1):46-52

https://doi.org/10.5271/sjweh.1735

Issue date: Feb 1991

Carpal tunnel syndrome among ski manufacturing workers. by Barnhart S, Demers PA, Miller M, Longstreth WT Jr, Rosenstock L

Affiliation: Department of Medicine, University of Washington, Seattle.

This article in PubMed: www.ncbi.nlm.nih.gov/pubmed/2047806 


\title{
Carpal tunnel syndrome among ski manufacturing workers
}

\author{
by Scott Barnhart, MD, MPH, ${ }^{1}$ Paul A Demers, MS, ${ }^{1}$ Mary Miller, ARNP, MN, ${ }^{1}$ \\ WT Longstreth, Jr, MD, MPH, ${ }^{2}$ Linda Rosenstock, MD, MPH ${ }^{1}$
}

\begin{abstract}
BARNHART S, DEMERS PA, MILLER M, LONGSTRETH WT JR, ROSENSTOCK L. Carpal tunnel syndrome among ski manufacturing workers. Scand $J$ Work Environ Health 1991;17:46-52. Carpal tunnel syndrome is a common disorder marked by pain and dysesthesias of the upper extremities. As a test of the hypothesis that carpal tunnel syndrome is associated with occupational risk factors, jobs at a ski assembly plant were classified as repetitive and nonrepetitive. The prevalence of carpal tunnel syndrome among 106 employees with repetitive jobs was compared with that among 67 employees with nonrepetitive jobs. The data collection included a questionnaire, a physical examination, and the measurement of distal sensory latencies of the median and ulnar nerves. Carpal tunnel syndrome was present in either or both hands in $15.4 \%$ of those workers with repetitive jobs, but only in $3.1 \%$ of those workers with nonrepetitive jobs (crude prevalence ratio 4.92, $95 \%$ confidence interval $1.17-20.7$ ). The conclusion was drawn that carpal tunnel syndrome is associated with jobs requiring frequent and sustained hand work.
\end{abstract}

Key terms: neuropathy, occupation.

Carpal tunnel syndrome is a common disorder of the upper extremities characterized by pain, dysesthesias, and weakness resulting from compression of the median nerve as it crosses the wrist. Carpal tunnel syndrome has been associated with several risk factors, including female sex, diabetes, acromegaly, hypothyroidism, rheumatoid arthritis, narrow carpal tunnel, and occupation (1-10). Purported occupational risk factors include repetitive work, forceful gripping, and exposure to vibration $(2-5,8,9)$. Prior studies in the workplace have used clinical symptoms and physical examination only to define carpal tunnel syndrome, and they have not employed electrophysiological testing. We hypothesized that, at a local ski assembly plant, carpal tunnel syndrome would be associated with repetitive work. To test this hypothesis, we used a cross-sectional study incorporating electrophysiological tests, physical examinations, and questionnaires to compare the prevalence of carpal tunnel syndrome between workers with jobs classified as repetitive and those with nonrepetitive jobs.

\section{Subjects and methods}

The study was conducted at a ski assembly plant which employed approximately 400 workers. The company

1 Occupational Medicine Program, Departments of Medicine and Environmental Health, University of Washington, Seattle, Washington, United States.

2 Division of Neurology, Department of Medicine, University of Washington, Seattle, Washington, United States.

Reprint requests to: Dr S Barnhart, Occupational Medicine Program, 325 Ninth Avenue, ZA-66, Seattle, WA 98104, USA. provided a list of all jobs in the facility. The study sample was recruited after the jobs had been classified as repetitive or nonrepetitive with respect to stress on the wrist by one of the authors (PD). Only jobs involving five or more people and jobs which clearly were highly repetitive or not repetitive were selected. Jobs for which classification was less obvious, such as those which might involve variable degrees of repetitive work, were not classified. The criteria for repetitive jobs entailed repeated and/or sustained activities that involved (i) flexion, extension, or ulnar deviation of the wrist by 45 degrees; (ii) radial deviation of more than 30 degrees; or (iii) use of a pinch type grip. Nonrepetitive jobs included those that did not meet the criteria for repetitive jobs. There were 257 subjects who met the criteria for repetitive and nonrepetitive jobs who were invited to participate in the study. Participation was solicited by distribution of a letter and preaddressed stamped response postcard. After the data collection, but before any analyses were performed, the subjects in either group were excluded if they did not meet all of the following eligibility criteria: employed in any job by the company for at least six months prior to their evaluation, in the job used for this study within the past two weeks and for a minimum of 10 weeks, and not employed in the other risk category in the past six months.

Among the approximately 400 employees at the plant, 152 were classified as having repetitive jobs and 105 employees as having nonrepetitive jobs. Table 1 identifies the job classifications and participation rates for the repetitive and nonrepetitive jobs. The participation rates for the physical examination and nerve conduction velocity testing for those with repetitive jobs was $70 \%$, and for those with nonrepetitive jobs 
it was $64 \%$. The participants with repetitive jobs were older than the corresponding nonparticipants (35.0 versus 27.9 years), but the two groups had been employed for a similar number of years (5.0 versus 4.1 years). For those with nonrepetitive jobs there were no statistically significant differences in age between the participants and nonparticipants (41.2 versus 43.9 years) or years employed ( 9.5 versus 8.4 years). Of the 120 subjects with repetitive jobs who responded, 14 were excluded for failing to meet the eligibility criteria, and of the 105 subjects with nonrepetitive jobs four were similarly excluded. The questionnaire was filled out and returned after the subject had left the test site. It was returned by $80 \%$ of those recruited with repetitive jobs and by $85 \%$ of those with nonrepetitive jobs.

Among those with repetitive jobs, $55 \%$ were women, and among those with nonrepetitive jobs $36 \%$ were women (table 2). The subjects with repetitive jobs were younger, had been employed fewer years, and had fewer months at their jobs than the subjects with nonrepetitive jobs. Among those with repetitive jobs 48 were working in molding, 30 in sanding, 12 in finishing, 3 in silk screening, and 13 in quality assurance. Among those with nonrepetitive jobs 15 were in skilled trades (such as mechanics and machinists), 7 were material handlers, 9 were supervisors, 17 were in clerical positions, 11 were engineers, 3 were in building and grounds maintenance, and 5 were in quality assurance.
Subjects with a job description of quality assurance inspection appeared in both the repetitive and nonrepetitive groups, but those in the nonrepetitive group required less repetitive handling of the skis.

Data were collected after a written informed consent was obtained. Information was gathered with the use of a self-administered questionnaire, a directed physical examination, and electrophysiological testing. A nurse practitioner (MM), trained in electrophysiological testing and the assessment of musculoskeletal disease and ignorant of a subject's job status, performed the physical examination and testing. The physical examination included the assessment of Phalen's and Tinel's signs. The electrophysiological testing entailed measurement of antidromic sensory latencies for the median and ulnar nerves (Neurodiagnostics, Santa Ana, California, United States) over a 14-cm distance across the wrist (11). Skin temperature was measured with a thermistor, but the subjects were not excluded on the basis of skin temperature. An abnormal latency consistent with carpal tunnel syndrome was defined as a sensory latency of the median nerve that is at least $0.5 \mathrm{~ms}$ greater than the sensory latency of the ulnar nerve $(11-13)$. Because of subject refusal or absence of a defined wave of depolarization, results were unavailable for the nerve conduction velocity tests of 11 of 173 subjects' right hands and of 8 of 173 subjects' left hands.

Table 1. Participation rates by study group and sex.

\begin{tabular}{|c|c|c|c|c|c|c|}
\hline \multirow{2}{*}{ Group } & \multirow{2}{*}{$\begin{array}{l}\text { Total } \\
(\mathrm{N})\end{array}$} & \multirow{2}{*}{$\begin{array}{l}\text { Agreed to } \\
\text { participate } \\
\text { (N) }\end{array}$} & \multicolumn{2}{|c|}{$\begin{array}{l}\text { Received physical } \\
\text { examinationa }\end{array}$} & \multicolumn{2}{|c|}{$\begin{array}{l}\text { Returned } \\
\text { questionnaire }\end{array}$} \\
\hline & & & $\mathrm{N}$ & $\%$ & $\mathrm{~N}$ & $\%^{b}$ \\
\hline \multicolumn{7}{|l|}{ Repetitive } \\
\hline $\begin{array}{l}\text { Men } \\
\text { Women }\end{array}$ & $\begin{array}{l}81 \\
71\end{array}$ & $\begin{array}{l}58 \\
62\end{array}$ & $\begin{array}{l}48 \\
58\end{array}$ & $\begin{array}{l}59 \\
82\end{array}$ & $\begin{array}{l}36 \\
59\end{array}$ & $\begin{array}{l}75 \\
84\end{array}$ \\
\hline Total & 152 & 120 & 106 & 70 & 85 & 80 \\
\hline \multicolumn{7}{|c|}{ Nonrepetitive } \\
\hline $\begin{array}{l}\text { Men } \\
\text { Women }\end{array}$ & $\begin{array}{l}73 \\
32\end{array}$ & $\begin{array}{l}45 \\
26\end{array}$ & $\begin{array}{l}43 \\
24\end{array}$ & $\begin{array}{l}59 \\
75\end{array}$ & $\begin{array}{l}36 \\
21\end{array}$ & $\begin{array}{l}84 \\
88\end{array}$ \\
\hline Total & 105 & 71 & 67 & 64 & 57 & 85 \\
\hline
\end{tabular}

a Eighteen individuals were excluded.

b Percentage of those examined who returned the questionnaire.

Table 2. Age, sex, and duration of employment by study group.

\begin{tabular}{|c|c|c|c|c|c|c|}
\hline \multirow{2}{*}{ Group } & \multicolumn{2}{|c|}{ Age (years) } & \multicolumn{2}{|c|}{ Years at company } & \multicolumn{2}{|c|}{ Months at job } \\
\hline & Mean & SE & Mean & SE & Mean & SE \\
\hline \multicolumn{7}{|l|}{ Repetitive } \\
\hline $\begin{array}{l}\text { Men }(N=48) \\
\text { Women }(N=58)\end{array}$ & $\begin{array}{l}31.9 \\
37.6\end{array}$ & $\begin{array}{l}1.5 \\
1.4\end{array}$ & $\begin{array}{l}4.5 \\
5.6\end{array}$ & $\begin{array}{l}0.6 \\
0.6\end{array}$ & $\begin{array}{l}14.1 \\
18.8\end{array}$ & $\begin{array}{l}2.2 \\
2.3\end{array}$ \\
\hline Total $(N=106)$ & 35.0 & 1.0 & 5.1 & 0.4 & 16.6 & 1.6 \\
\hline \multicolumn{7}{|l|}{ Nonrepetitive } \\
\hline $\begin{array}{l}\text { Men }(N=43) \\
\text { Women }(N=24)\end{array}$ & $\begin{array}{l}39.9 \\
44.0\end{array}$ & $\begin{array}{l}1.7 \\
1.8\end{array}$ & $\begin{array}{l}9.7 \\
9.4\end{array}$ & $\begin{array}{l}0.8 \\
1.1\end{array}$ & $\begin{array}{l}42.3 \\
34.5\end{array}$ & $\begin{array}{l}3.1 \\
4.4\end{array}$ \\
\hline Total $(N=67)$ & 41.4 & 1.3 & 9.6 & 0.6 & 39.6 & 2.5 \\
\hline
\end{tabular}


Table 3. Prevalence of hand symptoms by study group. (95 $\% \mathrm{Cl}=95 \%$ confidence interval)

\begin{tabular}{|c|c|c|c|c|}
\hline Symptom & $\begin{array}{l}\text { Repetitive group } \\
(\mathrm{N}=85) \\
(\%)\end{array}$ & $\begin{array}{l}\text { Nonrepetitive group } \\
(\mathrm{N}=57) \\
(\%)\end{array}$ & $\begin{array}{l}\text { Prevalence } \\
\text { ratio }\end{array}$ & $95 \% \mathrm{Cl}$ \\
\hline \multicolumn{5}{|l|}{ Hand pain } \\
\hline $\begin{array}{l}\text { Right hand } \\
\text { Left hand } \\
\text { Either hand }\end{array}$ & $\begin{array}{l}83.5 \\
84.7 \\
87.1\end{array}$ & $\begin{array}{l}68.4 \\
64.9 \\
68.4\end{array}$ & $\begin{array}{l}1.22 \\
1.30 \\
1.27\end{array}$ & $\begin{array}{l}1.00-1.49 \\
1.06-1.61 \\
1.05-1.55\end{array}$ \\
\hline \multicolumn{5}{|l|}{ Paresthesias } \\
\hline $\begin{array}{l}\text { Right hand } \\
\text { Left hand } \\
\text { Either hand }\end{array}$ & $\begin{array}{l}82.4 \\
82.4 \\
84.7\end{array}$ & $\begin{array}{l}68.4 \\
63.2 \\
70.2\end{array}$ & $\begin{array}{l}1.20 \\
1.30 \\
1.21\end{array}$ & $\begin{array}{l}0.98-1.47 \\
1.05-1.63 \\
1.00-1.46\end{array}$ \\
\hline \multicolumn{5}{|c|}{ Nocturnal hand pain } \\
\hline $\begin{array}{l}\text { Right hand } \\
\text { Left hand } \\
\text { Either hand }\end{array}$ & $\begin{array}{l}63.5 \\
62.4 \\
67.1\end{array}$ & $\begin{array}{l}45.6 \\
42.1 \\
45.6\end{array}$ & $\begin{array}{l}1.39 \\
1.48 \\
1.47\end{array}$ & $\begin{array}{l}1.01-1.93 \\
1.05-2.09 \\
1.07-2.03\end{array}$ \\
\hline \multicolumn{5}{|c|}{ One or more symptoms } \\
\hline $\begin{array}{l}\text { Right hand } \\
\text { Left hand } \\
\text { Either hand }\end{array}$ & $\begin{array}{l}96.5 \\
92.9 \\
96.5\end{array}$ & $\begin{array}{l}82.5 \\
77.2 \\
82.5\end{array}$ & $\begin{array}{l}1.17 \\
1.20 \\
1.17\end{array}$ & $\begin{array}{l}1.03-1.33 \\
1.03-1.40 \\
1.03-1.33\end{array}$ \\
\hline
\end{tabular}

Table 4. Prevalence of physical signs by study group. (95\% Cl=95\% confidence interval)

\begin{tabular}{|c|c|c|c|c|}
\hline Hand & $\begin{array}{c}\text { Repetitive group } \\
(\mathrm{N}=106) \\
(\%)\end{array}$ & $\begin{array}{l}\text { Nonrepetitive group } \\
(\mathrm{N}=67) \\
(\%)\end{array}$ & $\begin{array}{l}\text { Prevalence } \\
\text { ratio }\end{array}$ & $95 \% \mathrm{Cl}$ \\
\hline \multicolumn{5}{|l|}{ Right } \\
\hline $\begin{array}{l}\text { Phalen's sign } \\
\text { Tinel's sign } \\
\text { One or more signs }\end{array}$ & $\begin{array}{r}26.4 \\
6.6 \\
30.2\end{array}$ & $\begin{array}{l}9.0 \\
3.0 \\
7.5\end{array}$ & $\begin{array}{l}2.95 \\
2.21 \\
4.05\end{array}$ & $\begin{array}{l}1.29-6.74 \\
0.47-10.33 \\
1.66-9.87\end{array}$ \\
\hline \multicolumn{5}{|l|}{ Left } \\
\hline $\begin{array}{l}\text { Phalen's sign } \\
\text { Tinel's sign } \\
\text { One or more signs }\end{array}$ & $\begin{array}{l}25.5 \\
17.0 \\
36.8\end{array}$ & $\begin{array}{r}7.5 \\
14.9 \\
16.4\end{array}$ & $\begin{array}{l}3.41 \\
1.14 \\
2.24\end{array}$ & $\begin{array}{l}1.38-8.43 \\
0.56-2.31 \\
1.24-4.06\end{array}$ \\
\hline \multicolumn{5}{|l|}{ Either } \\
\hline $\begin{array}{l}\text { Phalen's sign } \\
\text { Tinel's sign } \\
\text { One or more signs }\end{array}$ & $\begin{array}{l}34.0 \\
18.9 \\
45.3\end{array}$ & $\begin{array}{l}10.4 \\
16.4 \\
20.9\end{array}$ & $\begin{array}{l}3.25 \\
1.15 \\
2.17\end{array}$ & $\begin{array}{l}1.54-6.88 \\
0.59-2.24 \\
1.30-3.61\end{array}$ \\
\hline
\end{tabular}

Table 5. Mean sensory latencies of the median and ulnar nerves by study group.

\begin{tabular}{lccc}
\hline & \multicolumn{2}{c}{ Sensory latency (ms) } \\
\cline { 2 - 3 } Nerve & $\begin{array}{c}\text { Repetitive } \\
\text { group }\end{array}$ & $\begin{array}{c}\text { Non- } \\
\text { repetitive } \\
\text { group }\end{array}$ & P-value \\
\hline Median & 3.01 & 2.95 & 0.51 \\
$\quad \begin{array}{l}\text { Right hand } \\
\text { Left hand }\end{array}$ & 2.90 & 2.88 & 0.76 \\
$\begin{array}{l}\text { Ulnar } \\
\quad \text { Right hand }\end{array}$ & 2.71 & 2.98 & 0.001 \\
$\quad$ Left hand & 2.72 & 2.88 & 0.05 \\
$\begin{array}{l}\text { Median-ulnar } \\
\text { difference }\end{array}$ & & & \\
$\quad$ Right hand & 0.30 & 0.03 & 0.001 \\
$\quad$ Left hand & 0.19 & 0.00 & 0.04 \\
\hline
\end{tabular}

The questionnaire inquired whether the subjects had pain, numbness, or tingling in their hands or fingers or whether they awakened at night with hand, wrist, or arm pain. The responses to these questions were analyzed as the dichotomous variables never present versus present at least rarely or more. In addition, all the participants were queried about whether they had thyroid disease, diabetes mellitus, or arthritis; and the female participants were asked about their history with respect to the use of birth control pills, menopause, or gynecologic surgery.

The evaluations were made at the worksite. The subjects were given sufficient time off from work with pay to participate in the physical examination and nerve conduction velocity testing and were then given the questionnaire to fill out at home and return in a preaddressed stamped envelope.

The case definitions for carpal tunnel syndrome were as follows. Carpal tunnel syndrome was said to be present if the following were present on the ipsilateral side. Case Definition I - "electrophysiological criterion" defined as a distal sensory latency of the median nerve minus the distal sensory latency of the ulnar nerve of $\geq 0.5 \mathrm{~ms}$. Case Definition II - "electrophysiological 
criterion and signs" defined as the presence of the electrophysiological criterion and Phalen's sign or Tinel's sign. Case Definition III - "electrophysiological criterion and either signs and/or symptoms" defined as the presence of the electrophysiological criterion and signs and/or ever having had hand pain, tingling, numbness, or nocturnal hand pain.

Case definitions I and III were defined before the data collection was initiated. Case definition II, which did not require information on symptoms, was formulated before the data analysis was begun because some of the participants failed to return the questionnaire.

We compared the prevalence of carpal tunnel syndrome and upper extremity signs and symptoms among individuals in the repetitive versus nonrepetitive jobs by calculating prevalence ratios. Adjustment for sex and age (19-35 and $\geq 36$ years) was performed with the use of Mantel-Haenszel methods (14). All of the $95 \%$ confidence intervals were calculated with the method proposed by Greenland \& Robins (15). T-tests were used to compare the sensory latencies of the median and ulnar nerves of the two groups.

\section{Results}

Symptoms of ever having had hand pain, paresthesias, or nocturnal pain were more common in either or both hands among the subjects with repetitive jobs than among those with nonrepetitive jobs (table 3 ). The excess was the greatest with nocturnal pain. The subjects with repetitive jobs had Phalen's sign more frequently than those with nonrepetitive jobs [right hand preva- lence ratio (PR) 2.95, $95 \%$ confidence interval (95\% CI) 1.29-6.74; left hand PR 3.41, $95 \%$ CI 1.388.43 , and either or both hands PR 3.25, $95 \% \mathrm{CI}$ 1.54-6.88] (table 4). Tinel's sign was not, however, present significantly more frequently in one of the two groups.

The difference between the distal sensory latencies of the median and ulnar nerves was used as an indicator of median nerve dysfunction. The mean difference was found to be significantly greater for both the right and left hands of those with repetitive jobs than for those with nonrepetitive jobs (table 5). For both the right and left hand of those with repetitive jobs this difference was primarily due to a shorter mean sensory latency of the ulnar nerve.

Table 6 displays the prevalence and prevalence ratios for carpal tunnel syndrome in both groups for the three case definitions. For case definition I, which was based on the electrodiagnostic criterion, carpal tunnel syndrome was present in either or both hands of $35(34 \%)$ of those with repetitive jobs and in 12 $(19 \%)$ of those with nonrepetitive jobs (PR 1.8, $95 \%$ CI 1.01-3.20). For case definition II, based on the presence of electrodiagnostic criterion and at least one sign (Phalen's or Tinel's), carpal tunnel syndrome was present in either or both hands of $16(15.4 \%)$ of those with repetitive jobs and in $2(3.1 \%)$ of those with nonrepetitive jobs (PR $=4.92,95 \%$ CI 1.1720.7). Case definition III required the presence of either or both a sign or symptom and an abnormal electrodiagnostic study. Among those with repetitive jobs, $27(32.5 \%)$ met the requirements of case definition III for either or both hands, the corresponding num-

Table 6. Prevalence of carpal tunnel syndrome according to the case definitions and study group. $(95 \% \mathrm{Cl}=95 \%$ confidence interval)

\begin{tabular}{lcccccc}
\hline Definitiona & $\begin{array}{c}\text { Repetitive } \\
\text { group } \\
(\%)\end{array}$ & $\begin{array}{c}\text { Nonrepetitive } \\
\text { group } \\
(\%)\end{array}$ & $\begin{array}{c}\text { Crude } \\
\text { prevalence } \\
\text { ratio }\end{array}$ & $95 \% \mathrm{Cl}^{\mathrm{b}}$ & $\begin{array}{c}\text { Adjusted } \\
\text { prevalence } \\
\text { ratio }\end{array}$ & $95 \% \mathrm{Cl}^{\mathrm{c}}$ \\
\hline Case definition I & & & & & & \\
$\quad$ Right hand & 30.7 & 14.8 & 2.08 & $1.06-4.07$ & 2.32 & $1.10-4.89$ \\
$\quad$ Left hand & 20.8 & 9.4 & 2.22 & $0.95-5.20$ & 2.28 & $0.93-5.59$ \\
$\quad$ Either hand & 33.7 & 18.8 & 1.79 & $1.01-3.20$ & 1.90 & $1.01-3.59$ \\
Case definition II & 11.9 & 1.6 & 7.25 & $0.97-54.4$ & 5.18 & $0.67-40.2$ \\
$\quad$ Right hand & 7.9 & 1.6 & 5.07 & $0.65-39.6$ & 4.26 & $0.63-29.0$ \\
$\quad$ Left hand & 15.4 & 3.1 & 4.92 & $1.17-20.7$ & 3.95 & $1.00-15.8$ \\
$\quad$ Either hand & & & & & & \\
Case definition III & 30.0 & 13.2 & 2.27 & $1.05-4.89$ & 2.12 & $0.94-4.78$ \\
$\quad$ Right hand & 19.8 & 9.1 & 2.17 & $0.85-5.58$ & 1.86 & $0.72-4.78$ \\
Left hand & 32.5 & 18.2 & 1.79 & $0.94-3.39$ & 1.63 & $0.83-3.21$ \\
$\quad$ Either hand & & & & & & \\
\hline
\end{tabular}

a Carpal tunnel syndrome was said to be present if the following were present on the ipsilateral side: case definition I - "electrophysiological criterion" defined as a distal sensory latency of the median nerve minus the distal sensory latency of the ulnar nerve $\geq 0.5 \mathrm{~ms}$; case definition II - "electrophysiological criterion and signs" defined as the presence of the electrophysiological criterion and Phalen's or Tinel's sign; case definition III - "electrophysiological criterion and either signs and/or symptoms" defined as the presence of electrophysiological criterion and signs and/or ever having had hand pain, tingling, numbness, or nocturnal hand pain.

b $95 \% \mathrm{Cl}$ of the crude prevalence ratio.

c $95 \% \mathrm{Cl}$ of the adjusted prevalence ratio. 
ber being $10(18.2 \%)$ for those with nonrepetitive jobs (PR 1.79, 95 \% CI 0.94-3.39).

For those who met the criteria for case definition II for either or both hands, $12(66 \%)$ were women. The prevalences of hand pain, paresthesias, nocturnal pain, Phalen's sign, and Tinel's sign were 75,88 , 88,69 , and $38 \%$, respectively, for the right hand and $60,80,60,44$, and $55 \%$, respectively, for the left hand. The mean duration of hand pain was 32 months (standard error 13 months) for the right hand and 20 months (standard error 8 months) for the left hand. A history of thyroid disease, arthritis, diabetes mellitus, and, for women, the use of birth control pills, gynecologic surgery, and menopause was reported by 8.3 , $0.0,22.2,12.5,42.9$, and $21.7 \%$ respectively. Only diabetes mellitus was present more frequently among those with carpal tunnel syndrome than among those without $(P=0.01)$.

To assess potential confounding by sex and age, adjusted prevalence ratios were calculated for the three case definitions. The adjusted prevalence ratios for the presence of carpal tunnel syndrome in either or both hands were $1.9(95 \%$ CI $1.01-3.59)$ for case definition I, 3.95 (95\% CI 1.00-15.8) for case definition II, and $1.63(95 \% \mathrm{CI} 0.83-3.21$ ) for case definition III (table 6). The presence of other diseases possibly related to carpal tunnel syndrome, such as thyroid disease (including under or over activity of the thyroid), arthritis, or diabetes mellitus, was low in the study population and except for diabetes did not appear to confound the relationship between exposure group and carpal tunnel syndrome. Among the women, there were no differences in the use of birth control pills, history of menopause, or gynecologic surgery between those with and those without carpal tunnel syndrome. In an assessment of the potential confounding by differences in temperature, the mean temperature was compared between the participants with and those without abnormal electrodiagnostic tests. The mean skin temperature was $33.1^{\circ} \mathrm{C}$ for those with an abnormal electrodiagnostic study and $32.9^{\circ} \mathrm{C}$ for those with a normal study.

The fact that the prevalence ratios for all three case definitions remained well elevated after adjustment for sex and age indicates that our results are independent of these factors, although some confounding may be present. The use of the adjusted prevalence ratios alone, however, should be considered prudently, given that job assignments are rarely made independent of sex and the possibility that there may be a survivor effect operating (7).

\section{Discussion}

In a study that a priori classified subjects into repetitive and nonrepetitive jobs and defined carpal tunnel syndrome according to three separate case definitions, we have shown an association between occupational risk factors and carpal tunnel syndrome. These findings agree with the results of other studies demonstrating an association of carpal tunnel syndrome with grocery checking, assembly work, and meat cutting $(1-10)$. In a survey of supermarket checkers, Margolis \& Kraus (10) found a prevalence of $62.5 \%$ for symptoms consistent with carpal tunnel syndrome. But, for that study, the specificity of a case definition for carpal tunnel syndrome which relied solely on questionnaire responses is unknown. Using a questionnaire and a physical examination, Silverstein et al (7), in a survey of assembly workers, found the prevalence of carpal tunnel syndrome to be $0.6 \%$ for jobs not requiring repetitive or forceful hand motions, $1 \%$ for jobs requiring forceful hand motions, $2.1 \%$ for jobs requiring repetitive hand motion, and $5.6 \%$ for jobs requiring repetitive and forceful hand motions $(\mathrm{P}<0.05)$. The results of our study and those of others associating carpal tunnel syndrome with repetitive work are further supported by studies on the pathophysiology of carpal tunnel syndrome. Repetitive work results in mechanical stress on the median nerve, elevated carpal tunnel pressures, ischemia, and finally histological changes of the median nerve and connective tissue within the carpal tunnel (16-18).

While other studies have also associated carpal tunnel syndrome with repetitive work, no cross-sectional studies have incorporated the testing of nerve conduction velocity in their case definition. Although there is no ideal diagnostic standard for carpal tunnel syndrome, the use of nerve conduction velocity testing adds a quantifiable indicator of median nerve dysfunction. Given the potential for other illnesses such as tendonitis to confound results by causing nonspecific symptoms such as pain, the use of nerve conduction velocity testing increases the specificity of the three case definitions.

This study has several limitations. The validity of the job classification for those in nonrepetitive jobs was not substantiated by objective or quantifiable measures. The groups with repetitive and nonrepetitive jobs were not perfectly matched with respect to age, duration of employment, or sex. The longer duration of employment and the older age of those with nonrepetitive jobs would be expected, however, to minimize the differences in the prevalence of carpal tunnel syndrome between the groups. Sex appeared to be a confounder, but it did not fully explain the excess risk for carpal tunnel syndrome associated with repetitive work. While diabetes mellitus was present more commonly among those with carpal tunnel syndrome, the use of a criterion for an abnormal electrodiagnostic test which includes both the median and ulnar nerves should guard against bias due to sensory polyneuropathy alone. This finding may reflect, however, a greater susceptibility among those with diabetes mellitus.

The failure of some subjects to participate or to return their questionnaires may have contributed respondent bias to the results, but it is unlikely to account 
for a substantial fraction of the difference in the prevalence of carpal tunnel syndrome by the case definition on the basis of questionnaire responses. The participants in the repetitive group alone were older than the nonparticipants and may have introduced an age bias resulting in an overestimate in the number of cases. The years employed were, however, similar for the participants and nonparticipants, a finding suggesting that the workplace exposures were not different.

Those who had carpal tunnel syndrome, as defined by case definition II (presence of electrodiagnostic criteria and signs), returned their questionnaires at a lower rate than those not meeting this case definition. This differential response rate may have resulted in an underestimate of the prevalence of carpal tunnel syndrome when case definition III, which required questionnaire symptom responses, was used. The effect of this differential response on the presence of confounders cannot be ascertained. While the examiner was blinded to the occupation, clues provided by clothing (eg, dress clothes compared to work clothes) could have conceivably biased the observations.

The choice of using the difference between the sensory latencies of the median and ulnar nerves was made prior to the start of the study and was based on a desire to use each subject as his or her own referent and to minimize bias introduced by the presence of polyneuropathy (12-13). Even though absolute criteria for the prolongation of the sensory latency of the median nerve could have been chosen, this choice could have potentially introduced bias if a healthy worker effect was present, as was suggested by the shorter sensory latency of the ulnar nerve and lack of differences between the sensory latencies of the median nerve among those with repetitive jobs in comparison with those with nonrepetitive jobs. Finally, the case definitions were limited by the lack of a standard for the diagnosis of carpal tunnel syndrome. Thus, while some subjects could have been misclassified, the three case definitions reflect current clinical criteria for carpal tunnel syndrome, such as presence of symptoms, signs, and prolonged sensory latency of the median nerve.

Despite these limitations, the consistent finding of an excess of carpal tunnel syndrome by several different case definitions demonstrated a strong association between carpal tunnel syndrome and repetitive work. These findings have implications for the primary, secondary, and tertiary prevention of carpal tunnel syndrome. As a work-related illness, carpal tunnel syndrome should be amenable to primary prevention through modification of workplace risk factors. Repetitiveness, grip posture, force, and vibration have already been identified and should be minimized (3, 7 , 9). Although high-risk jobs can be identified, individuals likely to develop carpal tunnel syndrome when employed in these jobs cannot be identified on the basis of sex or physical characteristics. Thus preem- ployment screening is not appropriate. Rather, highrisk jobs should be modified. For patients who have carpal tunnel syndrome and are employed in jobs requiring frequent motions of the hands, avoidance of these exposures should be considered a component of therapy that is used prior to the consideration of surgical intervention.

We conclude that carpal tunnel syndrome is associated with repetitive work of the hands. Given the high prevalence of carpal tunnel syndrome among certain groups, prospective studies need to be done regarding the natural history of carpal tunnel syndrome and the effectiveness of preventive measures.

\section{Acknowledgments}

The support by the K-2 Corporation (Vashon Island, Washington 98070, United States) and its employees for the conduct of this study is gratefully acknowledged.

\section{References}

1. Stevens J, Sun S, Beard C. Carpal tunnel syndrome in Rochester, Minnesota, 1961-1980. Neurology 1988;38:134-8.

2. Barnhart S, Rosenstock L. Carpal tunnel syndrome in grocery checkers: a cluster of work-related illness. West J Med 1987;147:37-40.

3. Cannon L, Bernacki E, Walter S. Personal and occupational factors associated with carpal tunnel syndrome. J Occup Med 1981;23:255-8.

4. Falck B, Aarnio P. Left-sided carpal tunnel syndrome in butchers. Scand J Work Environ Health 1983;9: 291-7.

5. Masear V, Hayes J, Hyde A. An industrial cause of carpal tunnel syndrome. J Hand Surg 1986;11A:222-7.

6. Leach RE, Odom JA Jr. Systemic causes of carpal tunnel syndrome. Postgrad Med 1968;44:127-31.

7. Silverstein B, Fine L, Armstrong T. Occupational factors and carpal tunnel syndrome. Am J Ind Med 1987; $11: 343-58$.

8. Birkbeck M, Beer T. Occupation in relation to the carpal tunnel syndrome. Rheumatol Rehabil 1975;14:218.

9. Armstrong T, Chaffin D. The carpal tunnel syndrome and selected personal attributes. J. Occup Med 1979; $21: 481-6$.

10. Margolis W, Kraus J. The prevalence of carpal tunnel syndrome symptoms in female supermarket checkers. J Occup Med 1987;12:953-60.

11. DeLisa J, Mackenzie K. Manual of nerve conduction velocity technique. New York, NY: Raven Press, 1982.

12. Felsenthal G. Median and Ulnar distal motor and sensory latencies in the same normal subject. Arch Phys Med Rehabil 1977;58:297-302.

13. Feldman R, Jabre J. Electrodiagnostic aspects of carpal tunnel syndrome. In: Hadler N, ed. Clinical concepts in regional musculoskeletal illness. Orlando, FL: Grune and Stratton, 1987:217-25.

14. Kleinbaum DG, Kupper LL, Morgenstern H. Epidemiologic research, principles and quantative methods. New York, NY: Von Nostrand Reinhold, 1982.

15. Greenland S, Robins JM. Estimation of a common effect parameter from sparse follow-up data. Biometrics 1985;41:55-68.

16. Smith E, Sonstegard D, Anderson W. Carpal tunnel syn- 
drome: contribution of flexor tendons. Arch Phys Med Rehabil 1977;58:379-85

17. Gelberman R, Hergenroeder P, Hargens A, Lundborg $\mathrm{G}$, Akeson W. The carpal tunnel syndrome: a study of canal pressure. J Bone Jt Surg 1981;63A:380-3

18. Armstrong TJ, Castelli WA, Evans FG, Diaz-Perez R. Received for publication: 11 December 1989
Some histological changes in carpal tunnel contents and their biomechanical implication. J Occup Med 1984;26: 197-201. 